\title{
Hydroxymethylation and tumors: can 5- hydroxymethylation be used as a marker for tumor diagnosis and treatment?
}

\author{
Tianmin Xu ${ }^{*}$ (D) and Haoyue Gao
}

\begin{abstract}
5-Methylcytosine $(5 \mathrm{mC})$ is considered as a common epigenetic modification that plays an important role in the regulation of gene expression. At the same time, 5 -hydroxymethylcytosine $(5 \mathrm{hmC})$ has been found as an emerging modification of cytosine bases of recent years. Unlike $5 \mathrm{mC}$, global $5 \mathrm{hmC}$ levels vary from tissues that have differential distribution both in mammalian tissues and in the genome. DNA hydroxymethylation is the process that $5 \mathrm{mC}$ oxidates into $5 \mathrm{hmC}$ with the catalysis of TET (ten-eleven translocation) enzymes. It is an essential option of DNA demethylation, which modulates gene expression by adjusting the DNA methylation level. Various factors can regulate the demethylation of DNA, such as environmental toxins and mental stress. In this review, we summarize the progress in the formation of $5 \mathrm{hmC}$, and obtaining $5 \mathrm{hmC}$ in a cell-free DNA sample presents multiple advantages and challenges for the subject. Furthermore, the clinical potential for $5 \mathrm{hmC}$ modification in dealing with cancer early diagnosis, prognostic evaluation, and prediction of therapeutic effect is also mentioned.
\end{abstract}

Keywords: 5-Hydroxymethylcytosine, 5-Methylcytosine, DNA demethylation, Cancer epigenetics, Cell-free DNA

\section{Background}

In the process of carcinogenesis, changes in epigenome as early events are generally the same as changes in the genome, which can inactivate tumor suppressor genes and activate proto-oncogenes and play an essential role in the occurrence, development, invasion, and metastasis of tumor [1]. For the past few years, researchers have extended the studies on tumors to the field of epigenetics. During tumor malignancy, distinct epigenetic modifications such as histone modification, DNA methylation, and demethylation, non-coding RNA may become effective biomarkers for high-risk assessment, early diagnosis, prognosis, and reference for drug treatment [2]. In mammals, TET dioxygenase mediates the oxidation of $5 \mathrm{mC}$ to 5-hydroxymethylcytosine $(5 \mathrm{hmC})$, 5formylcytosine (5fC), and 5-carboxylcytosine $(5 \mathrm{caC})$. Then, replication-dependent $5 \mathrm{mC}$ dilution or thymine

\footnotetext{
*Correspondence: xutianmin@126.com

The Second Hospital of Jilin University, Changchun, Jilin, China
}

DNA glycosylase (TDG)-dependent base excision repair (BER) performed. Thus, 5 -methylcytosine $(5 \mathrm{mC})$ can be reverted to unmodified cytosine (C) [3]. In a series of oxidation reactions, 5 -hydroxymethylcytosine $(5 \mathrm{hmC})$ is the first product. 5-Methylcytosine $(5 \mathrm{mC})$ and $\alpha$ ketoglutarate $(\alpha-K G)$ formed $5 \mathrm{hmC}$ with iron and oxygen as cofactors under the catalysis of ten-eleven translocation (TET) family proteins (Fig. 1). TET enzymes can further oxidize $5 \mathrm{hmC}$ to produce 5formylcytosine and 5-carboxylcytosine [4,5]. Consistent with their relatively low content in the genome, $5 \mathrm{fC}$ and $5 \mathrm{caC}$ have poor stability [4-6].

There are two mechanisms of DNA demethylation: active demethylation and passive demethylation [7]. Active demethylation is that TET protein oxidized 5- $\mathrm{mC}$ to generate 5 - hmC, 5 -fC, and 5-caC. 5 -fC and 5-caC can directly start base excision repair (BER) to generate cytosine under thymine glycosylase (TDG). Passive demethylation is also called the deamination pathway. In the 


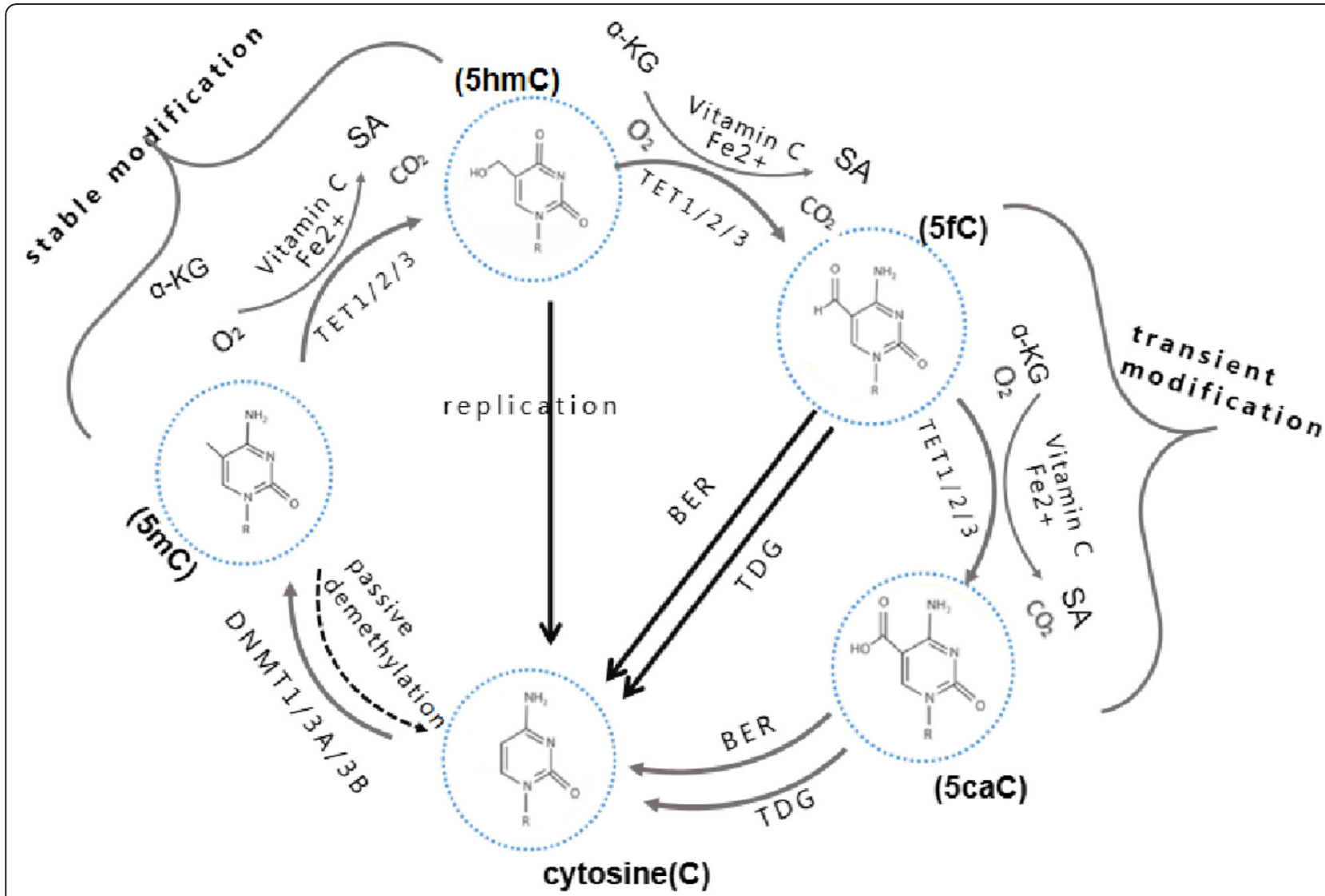

Fig. 1 Chemical structures of 5-methylcytosine $(5 \mathrm{mC})$ and its oxidized modifications. Cytosine is converted to 5-methylcytosine by both DNMT1 and DNMT3. 5-Methylcytosine is oxidized by TET1, TET2, or TET3 to yield 5-hydroxymethylcytosine (5hmC). By a similar reaction, using the same enzymes, 5-hydroxymethylcytosine is further oxidized to 5-formylcytosine (5fC) and 5-carboxycytosine (5caC). Both 5-formylcytosine and 5carboxycytosine are depyrimidated by the thymine DNA glycosylase (TDG) and processed by the base excision repair (BER) pathway. All these pathways could result in unmodified cytosine. $\mathrm{a}-\mathrm{KG}=$ a-ketoglutaric acid; $\mathrm{SA}=$ succinic acid

reaction, $5-\mathrm{mC}$ is converted into thymine under the deaminase, then initiate base excision repair with DNA thymine glycosylase and finally generate cytosine. The main methods of passive demethylation are the following [8]: (1) Oxidize the methyl group to carboxyl group and complete demethylation by decarboxylation. (2) Remove $5-\mathrm{mC}$ by BER pathway and replace with unmodified cytosine. (3) Specific deaminase recognizes and converts 5 - $\mathrm{mC}$ to $\mathrm{C}$. The 5-mC was converted to $\mathrm{C}$ through deamination to form a mismatch. Then, BER was started under TDG. (4) Demethylation through hydrolysis. 5$\mathrm{hmC}$ plays an essential role in both active demethylation and passive demethylation and is closely related to gene expression regulation. Different reaction processes regulate dynamic DNA demethylation. The availability and content of substrates and cofactors, post-transcription, and post-translation modifications of TET proteins are all factors. Previous studies that focused on structure and biochemical functions have elucidated how TET proteins and TDG mediate active DNA demethylation $[8,9]$. Among them, TET proteins may play a different role than the traditional catalytic enzyme. Further analysis is needed to clarify the function of TET proteins themselves and their role in DNA demethylation. Besides, with the continuous development of mapping and tracking technology of $5 \mathrm{mC}$ oxidation products, the functions of oxidation products 5-hydroxymethylcytosine $(5 \mathrm{hmC}), \quad 5$-formylcytosine $(5 \mathrm{fC})$, and 5carboxylcytosine $(5 \mathrm{caC})$ can be studied in depth. Different from $5 \mathrm{mC}$, the content of $5 \mathrm{hmC}$ in different tissue has better stability and stronger robustness, which presents tissue specificity, especially showing the differences between cancerous tissue and healthy tissue [10]. Since $5 \mathrm{hmC}$ is enriched in promoters, enhancers, and other transcriptional regulatory elements, it is more closely related to gene expression [11, 12]. This leads us to believe that it may have the potential of applying in the clinical diagnosis of tumors, like some vital regulatory molecules of epigenetics, and could be used to predict the metastasis, recurrence, and prognosis. Several surveys indicate that the potency and clinical convenience of tumor biomarkers are essential for the successful delivery of 
certain drugs and better clinical care for cancer patients. Due to the long incubation period of cancer and symptoms only start to emerge at an advanced stage, effective and timely treatment may not be available. Hence, efficient screening and early detection are particularly crucial to improve patient survival and quality of life $[11,13]$.

With the rapid development of liquid biopsy technique, cell-free DNA (cfDNA) originating from different tissues and entering blood circulation has become available research in recent years in the field of clinical diagnosis [14]. It only requires blood samples from cancer patients, with advantages of high efficiency, low cost, and smooth operation. From the perspective of patients, compliance is better and dynamic monitoring can be achieved. Most importantly, it makes up for the lack of inadequate acquisition due to the low content of $5 \mathrm{hmC}$ in tumor tissues $[15,16]$. In this review, we list the diagnostic function of $5 \mathrm{hmC}$ in cfDNA in early detection as well as its advantages in anticancer drug selection and efficacy monitoring. Meanwhile, in a variety of different types of cancer, the specific mechanisms by which epigenetic pattern changes identify oncogene mutations and dysregulations remain to be elucidated, and the problem of standardization requirements for all kinds of samples is yet to be solved.

\section{Advantages and disadvantages of ctDNA as $5 \mathrm{hmC}$ research sample}

Liquid biopsy is a diagnostic analysis of body fluid samples, such as circulating tumor cells (CTC), circulating tumor DNA (ctDNA), and exosome in the blood [17]. In recent years, ctDNA and cfDNA detection have been drawing much attention in diagnosis and treatment and become the research hotspot, as they have advantages of convenience, minimally invasive, convenient real-time monitoring, and easier to reflect the information of genome-wide tumorigenesis [17]. The methods used in ctDNA and cfDNA detection are known as polymerase chain reaction (PCR) technology (such as ARMS-PCR (amplification refractory mutation system) and digital PCR) and the next-generation sequencing technology (NGS) [18]. Although some ctDNA tests have been proved to have clinical validity and feasibility in analyzing some advanced cancer species, such as colorectal cancer, most of the ctDNA tests lack sufficient evidence to support their clinical practicability $[19,20]$. At this point, useful clinical evidence of ctDNA tests in early tumor detection, treatment monitoring, or residual tumor surveillance is limited, and there is also a lack of clinical practicability evidence.

Given the rapid progress of ctDNA research and clinical tools and guidelines, it will be necessary to reevaluate the pertinent literature so that standardized guidelines for various indexes of body fluid samples will be available soon [21]. There are many uncertain factors in the pre-processing steps of ctDNA test samples, and these variables may affect the sample purity, so as the subsequent test evaluation [22]. On the whole, many factors may affect the final result in the following steps, including blood drawing, collecting, processing, storage, transportation, and DNA extraction and purification. Also, biological factors related to patients may affect the release of cell-free DNA through the bloodstream, such as smoking, anemia, non-malignant diseases like inflammation, and autoimmune diseases (Fig. 2). However, the technology of sample control is still limited and many problems remain to be solved [21, 23]. To determine whether ctDNA can be used as an active marker in clinical practice, it is necessary to comprehensively evaluate its accuracy, sensitivity, specificity, and repeatability [24, 25]. At present, the method for assessing the accuracy and uniqueness of the plasma cfDNA test is mainly through methodological comparison with paired tissue samples [26]. Studies have shown that there may be differences between plasma ctDNA tests and biopsy results, which may be caused either by the performance of analysis (such as the analysis sensitivity) or by other biological properties. Multiple factors such as cancer type, tumor stage, temporal and spatial heterogeneity of tumor, and different sampling time between tissue and plasma can cause differences. Due to the low content of ctDNA in plasma, it is significant to explore the lower detection limit [27]. Considering the impact of biological property and nonbiological factors above, it is more objective and recommended to verify the detectability near the detection limit by incorporating cell lines or artificially constructing standardized samples [28]. The minimum analytical sensitivity and specificity required for ctDNA tests should be established on specific intended uses to facilitate its clinical application while emphasizing that mutation results must be combined with other clinical information to adjust the therapeutic regimen. The proportion of ctDNA in plasma cell-free DNA (also known as purity) varies from person to person. Similarly, the percentage of ctDNA in total cell-free DNA in different patients also has significant differences $[29,30]$. This explains why we need to study further the prognostic significance of mutation abundance in ctDNA tests.

As epigenetic changes in cell-free DNA (cfDNA) have been widely observed to show high sensitivity and specificity in disease detection and classification, including 5methylcytosine $(5 \mathrm{mC})$ and 5-methylcytosine $(5 \mathrm{hmC})$, it is vital to collect and integrate the bioinformation of cfDNA for future clinical application. However, due to the lack of effective collection, standardized quality control, and analysis procedures, the clinical utilization of these data cannot be effectively realized. CFEA (http:// 


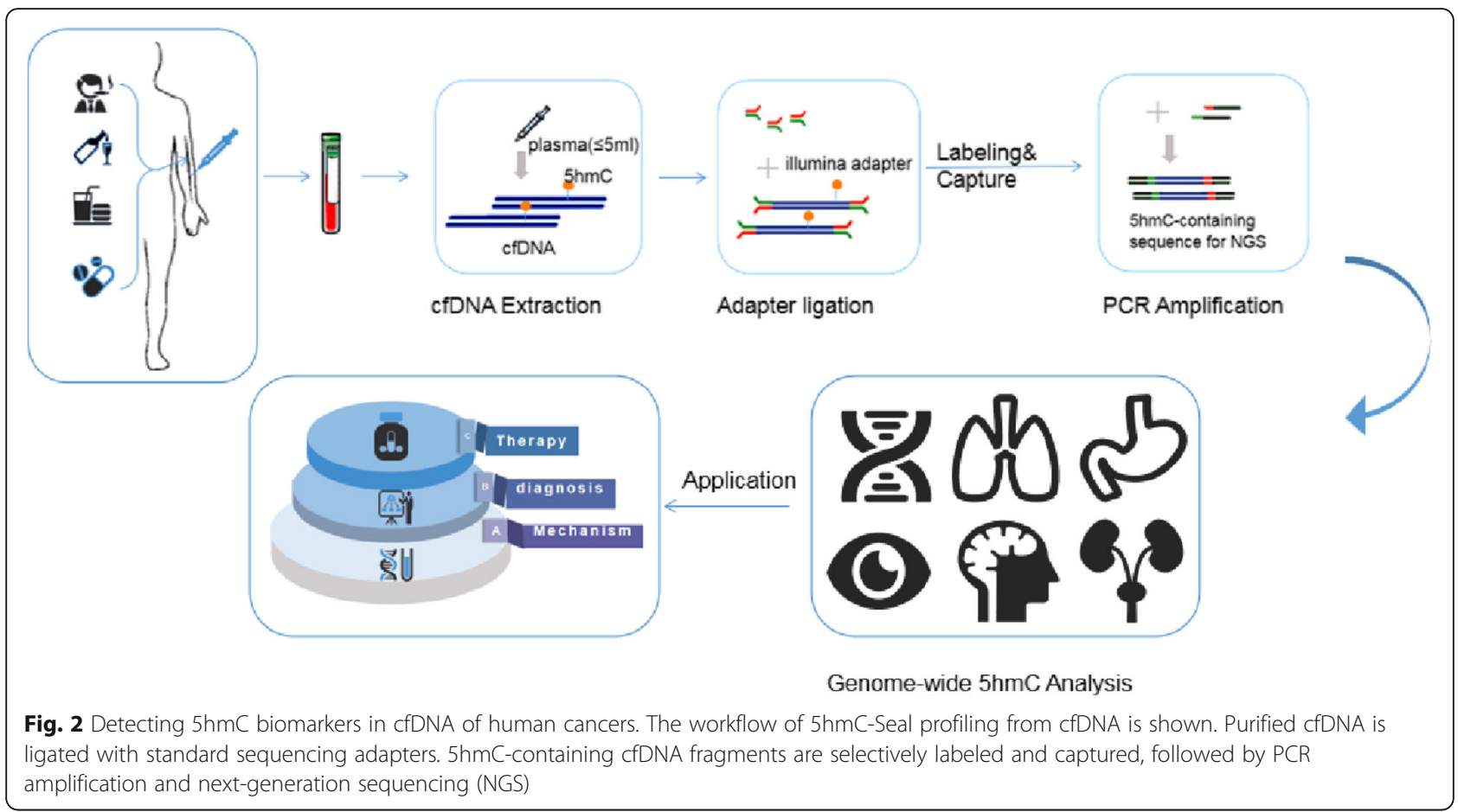

www.bio-data.cn/ CFEA) is a cell-free epigenome database used to involve $5 \mathrm{mC}$, $5 \mathrm{hmC}$, and NP (nucleosomal localization) of 27 kinds of human diseases. Bioinformation was quality controlled and standardized in the database. Besides, relevant clinical information was collected to facilitate the search and download of cellfree epigenome data. Users can better view and compare the development of the cfDNA epigenome in different stages of the tumor. The comprehensive and timely CFEA database has excellent potential for the development of liquid biopsy biomarkers for various human diseases [16].

\section{The value of $\mathbf{5 h m C}$ in tumor diagnosis}

Produced under the active demethylation mediated by the TET (ten-eleven transposition) dioxygenase family, $5 \mathrm{mC}$ is modified and oxidized to 5-hydroxymethyl cytosine $(5 \mathrm{hmC})$ and further oxidized to 5-formylcytosine (5fC) and 5-carboxycytosine $(5 \mathrm{caC})$ [10]. As a relatively stable DNA marker, $5 \mathrm{hmC}$ plays a role as a gene expression marker in the whole genome sequencing map of mammalian cells and tissues [31]. Since $5 \mathrm{hmC}$ is mainly distributed in the active transcriptional region, accompanied by open chromatin, and allowed histone modification, it is considered to be closely related to gene expression, which can be an ideal candidate biomarker with high chemical stability for cancer diagnosis [14, 32]. When $5 \mathrm{mC}$ in cfDNA was sequenced with bisulfite as a high background level inhibitory marker, the results were severely disturbed by DNA degradation [33]. However, unlike $5 \mathrm{mC}, 5 \mathrm{hmC}$ can be mapped with a low level of DNA and highly sensitive selective chemical markers, and the identified $5 \mathrm{hmC}$ has cancer type specificity [34-36]. Changes in $5 \mathrm{hmC}$ rich in enhancers, gene bodies, and promoters are closely related to changes in gene expression levels [37]. They can reproduce changes in gene expression in different cell states. Therefore, it can be combined with $5 \mathrm{mC}$ in cfDNA of liquid biopsy for non-invasive diagnosis and prognosis. Sensitive detection of cytosine modification patterns is helpful to identify cancer-specific biomarkers, and dynamic monitoring $5 \mathrm{hmC}$ needs to be put into clinical use because of the lower cost of obtaining blood samples, higher patient compliance, and clinical convenience [38].

Further, researchers found that in lung cancer patients, the content of $5 \mathrm{hmC}$ in cfDNA decreased gradually, while in the liver and pancreatic cancer patients, cellfree hydroxymethylome had their disease-specific changes [14, 26, 39]. However, for HCC (hepatocellular carcinoma), after calculating the HCC scores of postoperative and recurrent HCC samples, the researchers learned that HCC scores could accurately follow up on the treatment and understand the recurrence status of patients [40, 41]. In combination with the HCC score, cell-free $5 \mathrm{hmC}$ sequencing provides an opportunity to detect HCC, monitor treatment outcomes, and monitor recurrence status [42]. The unbiased gene-level analysis of tSNE ( $\mathrm{t}$-distributed stochastic neighbor embedding) 
showed that HCC patients could be isolated from HBVinfected patients and healthy individuals by comparing the cell-free $5 \mathrm{hmC}$ pattern [43]. HCC-specific differentially expressed genes $(q<0.001$, fold change $>1.41$, 1006 genes) could isolate HCC from healthy populations and most HBV samples [44].

Researchers have reported that an improved hMe-seal method makes the quantitative analysis of low levels of $5 \mathrm{hmC}$ in cfDNA possible, which has significant advantages over traditional methods $[45,46]$. Firstly, hMe-seal does not further degrade cfDNA in samples, unlike the bisulfite method used for cell-free $5 \mathrm{mC}$ sequencing. Secondly, compared to genome-wide sequencing methods including mutation sequencing, the concentration of $5 \mathrm{hmC}$ not only improves the cost-effectiveness (10-20 million reads, $\sim 0.5$-fold human genome coverage) but more importantly enables the quantitative determination of $5 \mathrm{hmC}$ cfDNA from low-frequency tissue sources, such as blood cell samples [33, 46]. In addition to data of the gene body, $5 \mathrm{hmC}$ in non-coding regions can also be used as potential biomarkers to predict cancer types [47]. What is noteworthy is that different types of cancer exhibit specific patterns of cell-free hydromethylome, which leads us to think that we can use specific cell-free $5 \mathrm{hmC}$ characteristics to predict cancer types with high precision. In the process of step by step clinical application, this will comprehensively analyze and summarize the genetic and epigenetic changes of various tumor states and further enhance the level of individualized diagnosis and precision medicine (Fig 3).

\section{The potential value of $5 \mathrm{hmC}$ in different types of cancer}

The traditional view is that a tumor is due to gene mutation and amplification caused by carcinogenic factors, which could lead to the disorder of cell proliferation and differentiation [48]. However, with further understanding of cancer in recent years, researchers found that regulatory mechanisms of the non-coding region perform more critical roles in the occurrence and progression of the tumor [49-51]. For example, DNA methylation, histone modification, and chromatin structure mutation are all found to alter in multiple types of tumors $[52,53]$. Researchers found $5 \mathrm{mC}$ correlated with the initiation, progression, histological grade, and poor prognosis of human cancers. However, the biological significance of $5 \mathrm{hmC}$ in human cancer remains elusive [54]. Discovery of the mechanism for ten-eleven translocation enzymes (TET1, TET2, and TET3), which are capable of the oxidation $5 \mathrm{mC}$ to $5 \mathrm{hmC}$ and gene regulation, shows that cytosine methylation is essential in mammalian genomic DNA and transcriptional regulation $[55,56]$. Global loss of $5 \mathrm{hmC}$, associated with TET downregulation and alteration of TET functions, points to a link between cancer epigenetics and immunoregulation $[57,58]$.

If the usual way of DNA methylation which is mediated through the coordinated actions of several DNA methyltransferases (DNMTs) that transfer a methyl group from S-adenosyl methionine (SAM) to the carbon-5 position of cytosine does not occur, DNA

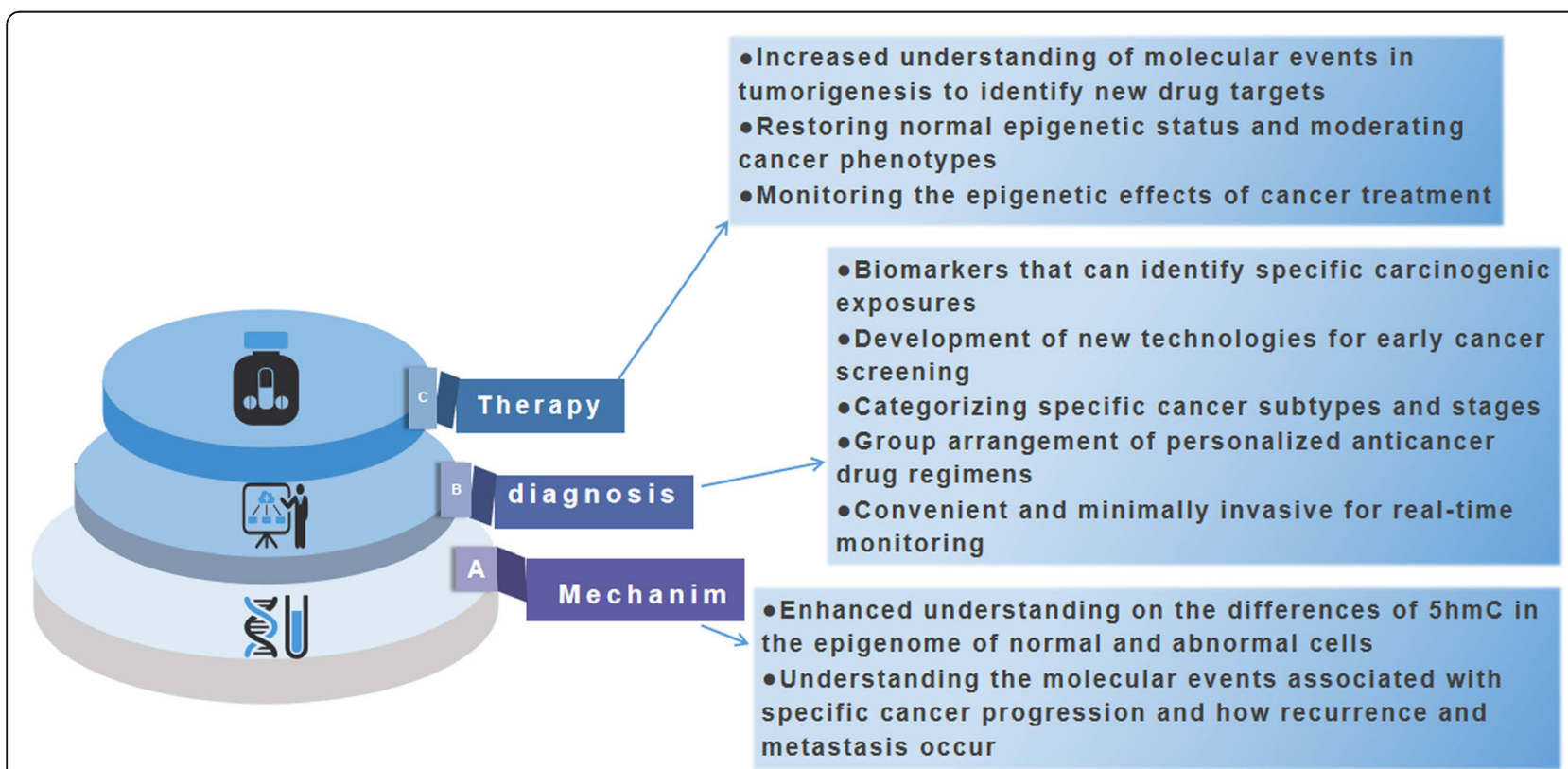

Fig. 3 Advances in genome-wide 5-hydroxymethylcytosine spectrum in tumor studies. Genome-wide 5-hydroxymethylcytosine spectrum could advance the field of cancer research. 5hmc-based analysis can help understand the underlying mechanisms associated with cancer progression, identify new diagnostic tools, and provide more effective drug regimens and efficacy monitoring for cancer treatment 
becomes progressively demethylated through a passive replication-dependent mechanism $[59,60]$. This dysregulation happens in both hematological and solid tumors, for example, colon, liver, lung, stomach, skin (melanoma), esophageal squamous cell carcinoma, prostate, blood, and breast tumors [61-63]. The most important thing is that the reduction of TET1 expression appears to be a tumor suppressor gene that can promote the growth and metastasis of cancer [64-66]. Thus, investigating the underlying molecular mechanisms between DNMTs and cancer is of great importance for therapeutic strategies.

\section{$5 \mathrm{hmC}$ and malignant melanoma}

Melanoma is a common and aggressive form of cancer, which makes the diagnosis very difficult. Even in the same pathology, the outcomes can vary significantly for lesions $[67,68]$. For now, there is only one panel of 31 RNA-based prognostic biomarkers known as Decision Dx-Melanoma that claims to improve prognostic predictions, which is only offered by a single laboratory in the USA $[69,70]$. The decreased expression of $5 \mathrm{hmC}$ in malignant tissue has been shown consistently in a wide range of different cancers, including melanoma [71-73]. Also, the loss of $5 \mathrm{hmC}$ in melanoma has been reported to lead to reduced survival, the decrease of $5 \mathrm{hmC}$ was positively correlated with the prognosis of malignant melanoma [74]. At the same time, TET2 reduced the expression in different pathological stages of malignant melanoma [75]. Along with the TET2 reducing, the tumor became more malignant [76, 77].

Clinically, the detection of $5 \mathrm{hmC}$ in the skin section of malignant melanoma guides the early diagnosis and prognosis [78]. Besides, $5 \mathrm{hmC}$ showed a similarly low level, whether it was from an exposed part [79]. It suggests that the low content of $5 \mathrm{hmC}$ may not be correlated with ultraviolet light [80]. These all suggest that $5 \mathrm{hmC}$ may be a viable prognostic biomarker in melanoma [81, 82].

\section{5hmC and breast cancer}

Breast cancer (BC) is a very heterogeneous disease characterized by different molecular and histopathological features; responses to treatment of its subtypes differ based on estrogen receptor, progesterone receptor, and human epidermal growth factor receptor 2 (HER2) status $[83,84]$. The complexity has been a big challenge for researchers and clinicians to stratify breast tumors. By evaluating a total of 15 pairs of normal and carcinoma samples in human breast tissue, the results show the levels of $5 \mathrm{hmC}$ were dramatically reduced in cancer group compared with the healthy breast tissues [85]. $5 \mathrm{hmC}$ of stem cells in breast cancer patients has reduced [86]. The expression of $5 \mathrm{hmC}$ was observed by immunohistochemical staining [87]. Researchers found that the nucleus of the unmutated breast cancer cells was $5 \mathrm{hmC}$ positive, while the $5 \mathrm{hmC}$ in TET2-mutated tissue was negative [88]. In order to determine the prognostic role of TET family proteins and DNA glycosylase (TDG) in patients with early breast cancer, the expression of mRNAs encoding TET1-3 and TDG in 162 breast cancer tissues was quantified. The result that TET1 mRNA was significantly related to overall survival [89], as well as TET3 and TDG mRNAs were independent prognostic factors for patients, suggests the relationship between DNA methylation and central signaling pathways involved in cancer [90]. There was more lymphocyte infiltration near the tumor cells. The expression of $5 \mathrm{hmC}$ in breast cancer of mutated TET2 was decreased [91, 92]. That is to say, abnormal regulation of TET2 may lead the hydroxymethylation of DNA in the wrong way. Furthermore, these all have contributed to finding the epigenetic medication, which can enhance the antitumor immune response.

\section{$5 \mathrm{hmC}$ and bladder cancer}

Despite significant advances in surgical techniques and adjuvant therapies, bladder cancer remains a highly prevalent and lethal malignancy [93]. Previous categories of tumor markers include proteomic markers [94, 95], genomic markers, and epigenetic markers [96, 97], and epigenetics is a field that combines genomics and proteomics [98]. The DNA methylation is the most common epigenetic change investigated in bladder tumor markers [99]. 5hmC level has seemed like an independent marker of bladder cancer gradually. In a study of 57 bladder cancer patients and 20 control individuals, by methylation-specific PCR, promoter methylation of Ecadherin, p16, p14, and RASSF1A in DNA isolated from exfoliated cells was evaluated [100].

Consistent with recent findings in different types of cancers, healthy bladder tissues showed intense nuclear $5 \mathrm{hmC}$ staining. However, a partial or complete loss of $5 \mathrm{hmC}$ was shown in bladder cancer. Patients with higher $5 \mathrm{hmC}$ levels had lived longer than the ones with lower levels; meanwhile, the lower $5 \mathrm{hmC}$ level, the higher stage and metastasis of the tumor. $5 \mathrm{hmC}$ is found to appear in gene-rich regions of the bladder in the normal genome and is correspondingly low in the cancer genome. The loss of $5 \mathrm{hmC}$ occurred in different cancer-related genes during bladder carcinogenesis. As the expression of TET2, L2HGDH, and vitamin C transporters (SVCT1 and SVCT2) was decreased in all bladder cancer cell lines, vitamin $C$ is found to be capable of increasing $5 \mathrm{hmC}$ as a cofactor of TET proteins [101]. The researchers then treated several bladder cancer cell lines with vitamin $\mathrm{C}$ at various concentrations and periods. It turned out that vitamin $\mathrm{C}$ increased the $5 \mathrm{hmC}$ levels in T24 cells, which depends on time and concentration. 
Moreover, similar effects were observed that $5 \mathrm{hmC}$ levels increased with vitamin $\mathrm{C}$, which inhibited cell growth in renal cancer [102]. It is also indicated that vitamin $\mathrm{C}$ can increase $5 \mathrm{hmC}$ levels in bladder cancer cells. Importantly, researchers observed that $5 \mathrm{hmC}$ promotes the activity of TET enzymes rather than increase the expression levels directly. It was also reported that high-dose vitamin $\mathrm{C}$ could restrain cancer cells by producing $\mathrm{H}_{2} \mathrm{O}_{2}$ [4], unlike low-dose vitamin $\mathrm{C}$, which suppressed cancer growth in an $\mathrm{H}_{2} \mathrm{O}_{2}$-independent way that included $5 \mathrm{hmC}$ restoration.

At present, there has been much research on $5 \mathrm{hmC}$ in the tumor. However, their specific function and mechanism in various cancers are not clear. Therefore, analyzing cancer-related genome-wide hydroxymethylated regions and binding sites of TET proteins will help to figure out their importance in cancer.

\section{Discussion}

DNA methylation is a process in which cytosine $(C)$ is catalyzed by DNA methyltransferase to produce $5 \mathrm{mC}$, and the product is called the "fifth base" of DNA. DNA hydromethylation refers to the oxidation of $5 \mathrm{mC}$ by TET to produce $5 \mathrm{hmC}$, the "sixth base" of DNA [103]. It is believed that methylation can inactive some genes, leading to gene silencing. However, demethylation can cause gene reactivation and expression, and the content of DNA methylation in tumors of different systems is still controversial. Studies have shown that the distribution of $5 \mathrm{hmC}$ is tissue-specific, and there are differences in the distribution of $5 \mathrm{hmC}$ in different organs and tissues. Also, the content of $5 \mathrm{hmC}$ in tissues and organs is affected by complex factors such as environmental toxins and the internal environment of the human body.

Because of the convenience of obtaining cfDNA and the smaller trauma to the human body, the study on $5 \mathrm{hmC}$ in cfDNA has attracted extensive attention from researchers. The acquisition and analysis of $5 \mathrm{hmC}$ in cfDNA provide a new perspective for the early diagnosis, effective treatment, and prognosis evaluation of tumors. With the development of biological information technology and high-throughput sequencing technology, the quantitative techniques of hydroxymethylation analysis such as hMeDIP-seq and TAB-Seq are becoming more and more mature, providing an advantageous method for DNA hydroxymethylation modification research in the tumor. The exploration of tumor-related genome-wide methylation regions is conducive to the in-depth understanding of the role of DNA hydromethylation modification in the development of solid tumors and hematological tumors, to find new tumor molecular markers and therapeutic targets, which may become a research hotspot in the next stage of methylation modified tumors.
In recent years, researches on hydromethylation mainly focus on tumors and psychiatric diseases [104, 105]. Studies have shown that during organ maturation and drug-induced response, $5 \mathrm{hmC}$ analysis can be used as an indicator of cell status and contribute to the identification of toxic carcinogen exposure [106, 107]. Dynamic enrichment patterns of methylation and hydromethylation markers may enable us to identify target genes for epigenetic modifications associated with prostate cancer [108]. Through a comprehensive analysis of global DNA methylation and hydroxymethylation in tumors and healthy tissues, colorectal cancer-related genes can be screened [109]. By changing the DNA methylation state, $5 \mathrm{hmC}$ can prevent the inactivation of some tumor suppressor genes and apoptotic genes. The decreased level of $5 \mathrm{hmC}$ leads to the lack of gene protection and the occurrence of tumors.

Although studies have suggested that methylation modification is associated with tumorigenesis and progression, studies on hydromethylation in ctDNA are still lacking. Moreover, the mechanism by which DNA methylation and hydroxymethylation affect oncogenesis and progression in different systems has not been clearly studied, and the specific role of epigenetic modification needs to be further explored. However, due to the complexity of biopsy required for the diagnosis of most tumors and cfDNA content in peripheral blood samples is susceptible to many external factors, it remains to be further studied whether other methods can be used to replace puncture biopsy in the future. What is the preference of hydromethylation in tumor-related genes for CpG sites? Which TET enzyme is involved in hydroxymethylation modification? How does hydromethylation status of specific gene promoters change after treatment? These problems need to be further explored.

\section{Conclusions}

As the intermediate product of cytosine modification, $5 \mathrm{hmC}$ has offered a broad perspective of the epigenetic regulation process. $5 \mathrm{hmC}$ is a prospective marker, which correlates to different stages of cancer. Future research may be inclined to explain the connection between $5 \mathrm{hmC}$ and intractable diseases, especially in early detection of tumors and the prediction of chemotherapeutic resistance. As far as the environment is concerned, its variety influences epigenetic modification, so as environmental toxins. After understanding the changes in $5 \mathrm{hmC}$, we will get more details about abnormal reactions caused by DNA hydroxymethylation. The relationship between $5 \mathrm{hmC}$ and the human body is expected to be a current issue in future research.

\section{Acknowledgements}

This work was supported by grants from the National Key Research and Development Plan (2016YFC1302900), Jilin Province Science and Technology 
Funds (20180201032YY, 20150204007YY, and 20140204022YY), Jilin Province Development and Reform Commission Funds (2014G073,2016C046-2), and Education Department of Jilin Province Funds (JJKH20170804KJ).

\section{Authors' contributions}

Haoyue Gao participated in the conception and design of the study and contributed to drafting the article. Tianmin Xu revised it critically for relevant intellectual content. All authors have read and approved the final submitted manuscript.

\section{Availability of data and materials}

The datasets generated/analyzed during the current study are available.

\section{Ethics approval and consent to participate}

Not applicable

\section{Consent for publication}

Consent for publication was obtained from the participants.

\section{Competing interests}

The authors declare that there is no conflict of interest regarding the publication of this article.

\section{Received: 18 February 2020 Accepted: 22 April 2020} Published online: 06 May 2020

\section{References}

1. Kelly AD, Issa JJ. The promise of epigenetic therapy: reprogramming the cancer epigenome. Curr Opin Genet Dev. 2017;42:68-77.

2. Kanwal R, Gupta S. Epigenetic modifications in cancer. Clin Genet. 2012; 81(4):303-11.

3. Shen L, Zhang Y. Enzymatic analysis of Tet proteins: key enzymes in the metabolism of DNA methylation. Methods Enzymol. 2012;512:93-105.

4. Ito S, Shen L, Dai Q, Wu SC, Collins LB, Swenberg JA, et al. Tet proteins can convert 5-methylcytosine to 5-formylcytosine and 5-carboxylcytosine. Science. 2011:333(6047):1300-3.

5. Pfaffeneder T, Hackner B, Truss M, Munzel M, Muller M, Deiml CA, et al. The discovery of 5-formylcytosine in embryonic stem cell DNA. Angew Chem Int Ed Engl. 2011;50(31):7008-12.

6. He YF, Li BZ, Li Z, Liu P, Wang Y, Tang Q, et al. Tet-mediated formation of 5carboxylcytosine and its excision by TDG in mammalian DNA. Science. 2011; 333(6047):1303-7.

7. Kroeze LI, van der Reijden BA, Jansen JH. 5-Hydroxymethylcytosine: an epigenetic mark frequently deregulated in cancer. Biochim Biophys Acta. 2015;1855(2):144-54.

8. Zhu JK. Active DNA demethylation mediated by DNA glycosylases. Annu Rev Genet. 2009:43:143-66.

9. Huang $H$, Jiang $X$, Li Z, Li Y, Song CX, He C, et al. TET1 plays an essential oncogenic role in MLL-rearranged leukemia. Proc Natl Acad Sci U S A. 2013; 110(29):11994-9.

10. Klungland A, Robertson AB. Oxidized C5-methyl cytosine bases in DNA: 5Hydroxymethylcytosine; 5-formylcytosine; and 5-carboxycytosine. Free Radic Biol Med. 2017;107:62-8

11. Kranzhofer DK, Gilsbach R, Gruning BA, Backofen R, Nuhrenberg TG, Hein L. 5'-Hydroxymethylcytosine precedes loss of CpG methylation in enhancers and genes undergoing activation in cardiomyocyte maturation. PLoS One. 2016;11(11):e0166575.

12. Kim M, Costello J. DNA methylation: an epigenetic mark of cellular memory. Exp Mol Med. 2017;49(4):e322.

13. Zhang J, Han X, Gao C, Xing Y, Qi Z, Liu R, et al. 5-Hydroxymethylome in circulating cell-free DNA as a potential biomarker for non-small-cell lung cancer. Genomics Proteomics Bioinformatics. 2018:16(3):187-99.

14. Song $C X$, Yin S, Ma L, Wheeler A, Chen Y, Zhang Y, et al. 5Hydroxymethylcytosine signatures in cell-free DNA provide information about tumor types and stages. Cell Res. 2017:27(10):1231-42.

15. Shahal T, Koren O, Shefer G, Stern N, Ebenstein Y. Hypersensitive quantification of global 5-hydroxymethylcytosine by chemoenzymatic tagging. Anal Chim Acta. 2018;1038:87-96.

16. Yu F, Li K, Li S, Liu J, Zhang Y, Zhou M, et al. CFEA: a cell-free epigenome atlas in human diseases. Nucleic Acids Res. 2020;48(D1):D40-d4.
17. Fernandes Marques J, Pereira Reis J, Fernandes G, Hespanhol V, Machado JC, Costa JL. Circulating tumor DNA: a step into the future of cancer management. Acta Cytol. 2019;63(6):456-65.

18. Shen Z, Wu A, Chen X. Current detection technologies for circulating tumor cells. Chem Soc Rev. 2017;46(8):2038-56.

19. Tie J, Cohen JD, Wang Y, Christie M, Simons K, Lee M, et al. Circulating tumor DNA analyses as markers of recurrence risk and benefit of adjuvant therapy for stage III colon cancer. JAMA Oncol. 2019;5:1710.

20. Tie J, Wang Y, Tomasetti C, Li L, Springer S, Kinde I, et al. Circulating tumor DNA analysis detects minimal residual disease and predicts recurrence in patients with stage II colon cancer. Sci Transl Med. 2016;8(346):346ra92.

21. Volckmar AL, Sultmann H, Riediger A, Fioretos T, Schirmacher P, Endris V, et al. A field guide for cancer diagnostics using cell-free DNA: from principles to practice and clinical applications. Genes Chromosomes Cancer. 2018:57(3):123-39.

22. Merker JD, Oxnard GR, Compton C, Diehn M, Hurley P, Lazar AJ, et al. Circulating tumor DNA analysis in patients with cancer: American Society of Clinical Oncology and College of American Pathologists joint review. J Clin Oncol. 2018:36(16):1631-41.

23. Cheng F, Su L, Qian C. Circulating tumor DNA: a promising biomarker in the liquid biopsy of cancer. Oncotarget. 2016:7(30):48832-41.

24. Vymetalkova V, Cervena K, Bartu L, Vodicka P. Circulating cell-free DNA and colorectal cancer: a systematic review. Int J Mol Sci. 2018;19(11):3356.

25. Cree IA, Uttley L, Buckley Woods H, Kikuchi H, Reiman A, Harnan S, et al. The evidence base for circulating tumour DNA blood-based biomarkers for the early detection of cancer: a systematic mapping review. BMC Cancer. 2017;17(1):697.

26. Li W, Zhang $X$, Lu X, You L, Song Y, Luo Z, et al. 5-Hydroxymethylcytosine signatures in circulating cell-free DNA as diagnostic biomarkers for human cancers. Cell Res. 2017;27(10):1243-57.

27. Chen J, Chen J, He F, Huang Y, Lu S, Fan H, et al. Design of a targeted sequencing assay to detect rare mutations in circulating tumor DNA. Genet Test Mol Biomarkers. 2019;23(4):264-9.

28. Nikolaev S, Lemmens L, Koessler T, Blouin JL, Nouspikel T. Circulating tumoral DNA: preanalytical validation and quality control in a diagnostic laboratory. Anal Biochem. 2018;542:34-9.

29. Wyatt AW, Annala M, Aggarwal R, Beja K, Feng F, Youngren J, et al. Concordance of circulating tumor DNA and matched metastatic tissue biopsy in prostate cancer. J Natl Cancer Inst. 2017;109(12).

30. Barbany G, Arthur C, Lieden A, Nordenskjold M, Rosenquist R, Tesi B, et al. Cell-free tumour DNA testing for early detection of cancer - a potential future tool. J Intern Med. 2019;286(2):118-36.

31. Nestor CE, Ottaviano R, Reddington J, Sproul D, Reinhardt D, Dunican D, et al. Tissue type is a major modifier of the 5-hydroxymethylcytosine content of human genes. Genome Res. 2012;22(3):467-77.

32. Stroud H, Feng $S$, Morey Kinney S, Pradhan S, Jacobsen SE. 5 Hydroxymethylcytosine is associated with enhancers and gene bodies in human embryonic stem cells. Genome Biol. 2011:12(6):R54.

33. Liu Y, Siejka-Zielinska P, Velikova G, Bi Y, Yuan F, Tomkova M, et al. Bisulfitefree direct detection of 5-methylcytosine and 5-hydroxymethylcytosine at base resolution. Nat Biotechnol. 2019;37(4):424-9.

34. Qing $Y$, Tian Z, Bi Y, Wang Y, Long J, Song CX, et al. Quantitation and mapping of the epigenetic marker 5-hydroxymethylcytosine. Bioessays. 2017;39(5):1700010.

35. Nazor KL, Boland MJ, Bibikova M, Klotzle B, Yu M, Glenn-Pratola VL, et al. Application of a low cost array-based technique - TAB-Array - for quantifying and mapping both $5 \mathrm{mC}$ and $5 \mathrm{hmC}$ at single base resolution in human pluripotent stem cells. Genomics. 2014;104(5):358-67.

36. Mooijman D, Dey SS, Boisset JC, Crosetto N, van Oudenaarden A. Single-cell $5 \mathrm{hmC}$ sequencing reveals chromosome-wide cell-to-cell variability and enables lineage reconstruction. Nat Biotechnol. 2016;34(8):852-6.

37. Mellen M, Ayata P, Dewell S, Kriaucionis S, Heintz N. MeCP2 binds to $5 \mathrm{hmC}$ enriched within active genes and accessible chromatin in the nervous system. Cell. 2012;151(7):1417-30.

38. Yong E. Cancer biomarkers: written in blood. Nature. 2014;511(7511):524-6.

39. Li X, Liu Y, Salz T, Hansen KD, Feinberg A. Whole-genome analysis of the methylome and hydroxymethylome in normal and malignant lung and liver. Genome Res. 2016;26(12):1730-41.

40. Hlady RA, Sathyanarayan A, Thompson JJ, Zhou D, Wu Q, Pham K, et al. Integrating the epigenome to identify drivers of hepatocellular carcinoma. Hepatology. 2019;69(2):639-52.

41. Cai J, Chen L, Zhang Z, Zhang X, Lu X, Liu W, et al. Genome-wide mapping of 5-hydroxymethylcytosines in circulating cell-free DNA as a non-invasive 
approach for early detection of hepatocellular carcinoma. Gut. 2019;68(12): 2195-205.

42. Dong ZR, Zhang C, Cai JB, Zhang PF, Shi GM, Gao DM, et al. Role of 5hydroxymethylcytosine level in diagnosis and prognosis prediction of intrahepatic cholangiocarcinoma. Tumour Biol. 2015;36(4):2763-71.

43. Zhu X, Dresser K, Chen BJ. Loss of 5-hydroxymethylcytosine immunohistochemical expression is a useful diagnostic aid for distinguishing hepatocellular carcinoma in cytology fine needle aspiration specimens. Cytopathology. 2019;30(5):492-8

44. Ye C, Tao R, Cao Q, Zhu D, Wang Y, Wang J, et al. Whole-genome DNA methylation and hydroxymethylation profiling for HBV-related hepatocellular carcinoma. Int J Oncol. 2016;49(2):589-602.

45. Yu M, Hon GC, Szulwach KE, Song CX, Zhang L, Kim A, et al. Base-resolution analysis of 5-hydroxymethylcytosine in the mammalian genome. Cell. 2012; 149(6):1368-80.

46. Skvortsova K, Zotenko E, Luu PL, Gould CM, Nair SS, Clark SJ, et al. Comprehensive evaluation of genome-wide 5-hydroxymethylcytosine profiling approaches in human DNA. Epigenetics Chromatin. 2017;10:16.

47. Bettegowda C, Sausen M, Leary RJ, Kinde I, Wang Y, Agrawal N, et al. Detection of circulating tumor DNA in early- and late-stage human malignancies. Sci Transl Med. 2014;6(224):224ra24.

48. Brison O. Gene amplification and tumor progression. Biochim Biophys Acta. 1993;1155(1):25-41.

49. Nakagawa $H$, Fujita M. Whole genome sequencing analysis for cancer genomics and precision medicine. Cancer Sci. 2018;109(3):513-22.

50. Khurana E, Fu Y, Chakravarty D, Demichelis F, Rubin MA, Gerstein M. Role of non-coding sequence variants in cancer. Nat Rev Genet. 2016;17(2):93-108.

51. Diederichs S, Bartsch L, Berkmann JC, Frose K, Heitmann J, Hoppe C, et al. The dark matter of the cancer genome: aberrations in regulatory elements, untranslated regions, splice sites, non-coding RNA and synonymous mutations. EMBO Mol Med. 2016;8(5):442-57.

52. Tai KY, Shiah SG, Shieh YS, Kao YR, Chi CY, Huang E, et al. DNA methylation and histone modification regulate silencing of epithelial cell adhesion molecule for tumor invasion and progression. Oncogene. 2007;26(27):3989-97

53. Lu TY, Kao CF, Lin CT, Huang DY, Chiu CY, Huang YS, et al. DNA methylation and histone modification regulate silencing of OPG during tumor progression. J Cell Biochem. 2009;108(1):315-25.

54. Putiri EL, Tiedemann RL, Thompson JJ, Liu C, Ho T, Choi JH, et al. Distinct and overlapping control of 5-methylcytosine and 5-hydroxymethylcytosine by the TET proteins in human cancer cells. Genome Biol. 2014;15(6):R81.

55. Schubeler D. Function and information content of DNA methylation. Nature. 2015;517(7534):321-6.

56. Feng L, Lou J. DNA methylation analysis. Methods Mol Biol. 1894;2019:181-227.

57. Qiu L, Liu F, Yi S, Li X, Liu X, Xiao C, et al. Loss of 5-hydroxymethylcytosine is an epigenetic biomarker in cutaneous T-cell lymphoma. J Invest Dermatol. 2018:138(11):2388-97.

58. Lio CJ, Yuita H, Rao A. Dysregulation of the TET family of epigenetic regulators in lymphoid and myeloid malignancies. Blood. 2019;134(18): 1487-97.

59. van der Wijst MG, Venkiteswaran $M$, Chen $H, X u$ GL, Plosch $T$, Rots MG. Local chromatin microenvironment determines DNMT activity: from DNA methyltransferase to DNA demethylase or DNA dehydroxymethylase. Epigenetics. 2015;10(8):671-6

60. Chen CC, Wang KY, Shen CK. The mammalian de novo DNA methyltransferases DNMT3A and DNMT3B are also DNA 5hydroxymethylcytosine dehydroxymethylases. J Biol Chem. 2012;287(40): 33116-21.

61. Kanazawa A, Tsukamoto T, Shimizu S, Yamamoto S, Murata A, Kubo S. Laparoscopic hepatectomy for liver cancer. Dig Dis. 2015;33(5):691-8.

62. Tekpli X, Urbanucci A, Hashim A, Vagbo CB, Lyle R, Kringen MK, et al. Changes of 5-hydroxymethylcytosine distribution during myeloid and lymphoid differentiation of CD34+ cells. Epigenetics Chromatin. 2016;9:21.

63. Tekpli X, Skaug V, Baera R, Phillips DH, Haugen A, Mollerup S. Estrogen receptor expression and gene promoter methylation in non-small cell lung cancer - a short report. Cell Oncol (Dordr). 2016;39(6):583-9.

64. Neri F, Incarnato D, Oliviero S. DNA methylation and demethylation dynamics. Oncotarget. 2015;6(33):34049-50.

65. Neri F, Dettori D, Incarnato D, Krepelova A, Rapelli S, Maldotti M, et al. TET1 is a tumour suppressor that inhibits colon cancer growth by derepressing inhibitors of the WNT pathway. Oncogene. 2015;34(32):4168-76.
66. Kundaje A, Meuleman W, Ernst J, Bilenky M, Yen A, Heravi-Moussavi A, et al. Integrative analysis of 111 reference human epigenomes. Nature. 2015; 518(7539):317-30

67. Eggermont AMM, Blank CU, Mandala M, Long GV, Atkinson V, Dalle S, et al. Adjuvant pembrolizumab versus placebo in resected stage III melanoma. N Engl J Med. 2018;378(19):1789-801.

68. Gould Rothberg BE, Rimm DL. Biomarkers: the useful and the not so usefulan assessment of molecular prognostic markers for cutaneous melanoma. J Invest Dermatol. 2010;130(8):1971-87.

69. Yelamos O, Gerami P. Predicting the outcome of melanoma: can we tell the future of a patient's melanoma? Melanoma Manag. 2015;2(3):217-24.

70. Gerami P, Cook RW, Wilkinson J, Russell MC, Dhillon N, Amaria RN, et al. Development of a prognostic genetic signature to predict the metastatic risk associated with cutaneous melanoma. Clin Cancer Res. 2015:21(1):175-83.

71. Jin SG, Wu X, Li AX, Pfeifer GP. Genomic mapping of 5hydroxymethylcytosine in the human brain. Nucleic Acids Res. 2011;39(12): 5015-24.

72. Gu TP, Guo F, Yang H, Wu HP, Xu GF, Liu W, et al. The role of Tet3 DNA dioxygenase in epigenetic reprogramming by oocytes. Nature. 2011; 477(7366):606-10

73. Tahiliani M, Koh KP, Shen Y, Pastor WA, Bandukwala H, Brudno Y, et al. Conversion of 5-methylcytosine to 5-hydroxymethylcytosine in mammalian DNA by MLL partner TET1. Science. 2009;324(5929):930-5.

74. Cimmino L, Abdel-Wahab O, Levine RL, Aifantis I. TET family proteins and their role in stem cell differentiation and transformation. Cell Stem Cell. 2011;9(3):193-204

75. Gambichler T, Sand M, Skrygan M. Loss of 5-hydroxymethylcytosine and ten-eleven translocation 2 protein expression in malignant melanoma. Melanoma Res. 2013:23(3):218-20.

76. Uchiyama R, Uhara H, Uchiyama A, Ogawa E, Takazawa Y, Ashida A, et al. 5Hydroxymethylcytosine as a useful marker to differentiate between malignant melanomas and benign melanocytic nevi. J Dermatol Sci. 2014; 73(2):161-3

77. Mikoshiba Y, Ogawa E, Uchiyama R, Uchiyama A, Uhara H, Okuyama R. 5Hydroxymethylcytosine is a useful marker to differentiate between dermatofibrosarcoma protuberans and dermatofibroma. J Eur Acad Dermatol Venereol. 2016;30(1):130-1.

78. Song F, Amos Cl, Lee JE, Lian CG, Fang S, Liu H, et al. Identification of a melanoma susceptibility locus and somatic mutation in TET2. Carcinogenesis. 2014;35(9):2097-101.

79. Shibata T, Kokubu A, Miyamoto M, Sasajima Y, Yamazaki N. Mutant IDH1 confers an in vivo growth in a melanoma cell line with BRAF mutation. Am J Pathol. 2011;178(3):1395-402.

80. Munari E, Chaux A, Vaghasia AM, Taheri D, Karram S, Bezerra SM, et al. Global 5-hydroxymethylcytosine levels are profoundly reduced in multiple genitourinary malignancies. PLoS One. 2016;11(1):e0146302.

81. Ito S, D'Alessio AC, Taranova OV, Hong K, Sowers LC, Zhang Y. Role of Tet proteins in $5 \mathrm{mC}$ to $5 \mathrm{hmC}$ conversion, ES-cell self-renewal and inner cell mass specification. Nature. 2010;466(7310):1129-33.

82. Abbas O, Miller DD, Bhawan J. Cutaneous malignant melanoma: update on diagnostic and prognostic biomarkers. Am J Dermatopathol. 2014;36(5):363-79.

83. Wu SG, He ZY, Li Q, Li FY, Lin Q, Lin HX, et al. Predictive value of breast cancer molecular subtypes in Chinese patients with four or more positive nodes after postmastectomy radiotherapy. Breast. 2012;21(5):657-61.

84. Arvold ND, Taghian AG, Niemierko A, Abi Raad RF, Sreedhara M, Nguyen PL, et al. Age, breast cancer subtype approximation, and local recurrence after breast-conserving therapy. J Clin Oncol. 2011;29(29):3885-91.

85. Yang H, Liu Y, Bai F, Zhang JY, Ma SH, Liu J, et al. Tumor development is associated with decrease of TET gene expression and 5-methylcytosine hydroxylation. Oncogene. 2013;32(5):663-9.

86. Lorsbach RB, Moore J, Mathew S, Raimondi SC, Mukatira ST, Downing JR. TET1, a member of a novel protein family, is fused to MLL in acute myeloid leukemia containing the $t(10 ; 11)(q 22 ; q 23)$. Leukemia. 2003;17(3):637-41.

87. Tefferi A, Lim KH, Abdel-Wahab O, Lasho TL, Patel J, Patnaik MM, et al. Detection of mutant TET2 in myeloid malignancies other than myeloproliferative neoplasms: CMML, MDS, MDS/MPN and AML. Leukemia. 2009;23(7):1343-5.

88. Abdel-Wahab O, Mullally A, Hedvat C, Garcia-Manero G, Patel J, Wadleigh M, et al. Genetic characterization of TET1, TET2, and TET3 alterations in myeloid malignancies. Blood. 2009;114(1):144-7. 
89. Liu C, Liu L, Chen X, Shen J, Shan J, Xu Y, et al. Decrease of 5hydroxymethylcytosine is associated with progression of hepatocellular carcinoma through downregulation of TET1. PLoS One. 2013;8(5):e62828.

90. Yang L, Yu SJ, Hong Q, Yang Y, Shao ZM. Reduced expression of TET1, TET2, TET3 and TDG mRNAs are associated with poor prognosis of patients with early breast cancer. PLoS One. 2015;10(7):e0133896.

91. Wu MZ, Chen SF, Nieh S, Benner C, Ger LP, Jan Cl, et al. Hypoxia drives breast tumor malignancy through a TET-TNFalpha-p38-MAPK signaling axis. Cancer Res. 2015;75(18):3912-24.

92. Tefferi A, Levine RL, Lim KH, Abdel-Wahab O, Lasho TL, Patel J, et al. Frequent TET2 mutations in systemic mastocytosis: clinical, KITD816V and FIP1L1-PDGFRA correlates. Leukemia. 2009;23(5):900-4.

93. Jemal A, Siegel R, Ward E, Hao Y, Xu J, Murray T, et al. Cancer statistics, 2008. CA Cancer J Clin. 2008;58(2):71-96.

94. Petricoin EF, Zoon KC, Kohn EC, Barrett JC, Liotta LA. Clinical proteomics: translating benchside promise into bedside reality. Nat Rev Drug Discov. 2002;1(9):683-95.

95. Schiffer E, Mischak H, Theodorescu D, Vlahou A. Challenges of using mass spectrometry as a bladder cancer biomarker discovery platform. World J Urol. 2008;26(1):67-74.

96. Lodde $\mathrm{M}$, Fradet $\mathrm{Y}$. The detection of genetic markers of bladder cancer in urine and serum. Curr Opin Urol. 2008:18(5):499-503.

97. Vrooman OP, Witjes JA. Molecular markers for detection, surveillance and prognostication of bladder cancer. Int J Urol. 2009:16(3):234-43.

98. Taylor SE, Li YH, Smeriglio P, Rath M, Wong WH, Bhutani N. Stable 5hydroxymethylcytosine (5hmC) acquisition marks gene activation during chondrogenic differentiation. J Bone Miner Res. 2016;31(3):524-34.

99. Kim YK, Kim WJ. Epigenetic markers as promising prognosticators for bladder cancer. Int J Urol. 2009;16(1):17-22.

100. Lin HH, Ke HL, Huang SP, Wu WJ, Chen YK, Chang LL. Increase sensitivity in detecting superficial, low grade bladder cancer by combination analysis of hypermethylation of E-cadherin, p16, p14, RASSF1A genes in urine. Urol Oncol. 2010;28(6):597-602.

101. Jankowska AM, Szpurka H, Tiu RV, Makishima H, Afable M, Huh J, et al. Loss of heterozygosity 4q24 and TET2 mutations associated with myelodysplastic/myeloproliferative neoplasms. Blood. 2009;113(25):6403-10.

102. Lian CG, Xu Y, Ceol C, Wu F, Larson A, Dresser K, et al. Loss of 5hydroxymethylcytosine is an epigenetic hallmark of melanoma. Cell. 2012; 150(6):1135-46.

103. Kraus TF, Guibourt V, Kretzschmar HA. 5-Hydroxymethylcytosine, the "Sixth Base", during brain development and ageing. J Neural Transm (Vienna). 2015;122(7):1035-43.

104. Rustad SR, Papale LA, Alisch RS. DNA methylation and hydroxymethylation and behavior. Curr Top Behav Neurosci. 2019:42:51-82.

105. Hack LM, Dick ALW, Provencal N. Epigenetic mechanisms involved in the effects of stress exposure: focus on 5-hydroxymethylcytosine. Environ Epigenet. 2016;2(3):dvw016.

106. Zhu T, Brown AP, Ji H. The emerging role of ten-eleven translocation 1 in epigenetic responses to environmental exposures. Epigenet Insights. 2020; 13. https://doi.org/10.1177/2516865720910155.

107. Thomson JP, Hunter JM, Lempiainen H, Muller A, Terranova R, Moggs JG, et al. Dynamic changes in 5-hydroxymethylation signatures underpin early and late events in drug exposed liver. Nucleic Acids Res. 2013;41(11):5639-54.

108. Kamdar SN, Ho LT, Kron KJ, Isserlin R, van der Kwast T, Zlotta AR, et al. Dynamic interplay between locus-specific DNA methylation and hydroxymethylation regulates distinct biological pathways in prostate carcinogenesis. Clin Epigenetics. 2016;8:32.

109. Gilat N, Tabachnik T, Shwartz A, Shahal T, Torchinsky D, Michaeli Y, et al. Single-molecule quantification of 5-hydroxymethylcytosine for diagnosis of blood and colon cancers. Clin Epigenetics. 2017:9:70.

\section{Publisher's Note}

Springer Nature remains neutral with regard to jurisdictional claims in published maps and institutional affiliations.

\section{Ready to submit your research? Choose BMC and benefit from:}

- fast, convenient online submission

- thorough peer review by experienced researchers in your field

- rapid publication on acceptance

- support for research data, including large and complex data types

- gold Open Access which fosters wider collaboration and increased citations

- maximum visibility for your research: over $100 \mathrm{M}$ website views per year

At BMC, research is always in progress.

Learn more biomedcentral.com/submissions 